\title{
DNA repair and crossing over favor similar chromosome regions as discovered in radiation hybrid of Triticum
}

Ajay Kumar ${ }^{1 \dagger}$, Filippo M Bassi ${ }^{1 \dagger}$, Etienne Paux ${ }^{2}$, Omar Al-Azzam³ ${ }^{3}$, Monika Michalak de Jimenez ${ }^{1}$, Anne M Denton ${ }^{3}$, Yong Q Gư ${ }^{4}$, Eric Huttner ${ }^{5}$, Andrzej Kilian, Sachin Kumar ${ }^{6}$, Aakash Goyal $^{6}$, Muhammad J lqbal', Vijay K Tiwari ${ }^{7}$, Munevver Dogramaci ${ }^{8}$, Harindra S Balyan ${ }^{6}$, Harcharan S Dhaliwal ${ }^{9}$, Pushpendra K Gupta ${ }^{6}$, Gursharn S Randhawa ${ }^{10}$, Catherine Feuillet ${ }^{2}$, Wojciech P Pawlowski ${ }^{11}$ and Shahryar F Kianian ${ }^{1 *}$

\begin{abstract}
Background: The uneven distribution of recombination across the length of chromosomes results in inaccurate estimates of genetic to physical distances. In wheat (Triticum aestivum L.) chromosome 3B, it has been estimated that $90 \%$ of the cross over events occur in distal sub-telomeric regions representing $40 \%$ of the chromosome. Radiation hybrid $(\mathrm{RH})$ mapping which does not rely on recombination is a strategy to map genomes and has been widely employed in animal species and more recently in some plants. RH maps have been proposed to provide i) higher and ii) more uniform resolution than genetic maps, and iii) to be independent of the distribution patterns observed for meiotic recombination. An in vivo RH panel was generated for mapping chromosome 3B of wheat in an attempt to provide a complete scaffold for this $\sim 1 \mathrm{~Gb}$ segment of the genome and compare the resolution to previous genetic maps.

Results: A high density RH map with 541 marker loci anchored to chromosome 3B spanning a total distance of 1871.9 CR was generated. Detailed comparisons with a genetic map of similar quality confirmed that $i)$ the overall resolution of the RH map was 10.5 fold higher and ii) six fold more uniform. A significant interaction ( $r=0.879$ at $p=0.01$ ) was observed between the DNA repair mechanism and the distribution of crossing-over events. This observation could be explained by accepting the possibility that the DNA repair mechanism in somatic cells is affected by the chromatin state in a way similar to the effect that chromatin state has on recombination frequencies in gametic cells.
\end{abstract}

Conclusions: The RH data presented here support for the first time in vivo the hypothesis of non-casual interaction between recombination hot-spots and DNA repair. Further, two major hypotheses are presented on how chromatin compactness could affect the DNA repair mechanism. Since the initial RH application 37 years ago, we were able to show for the first time that the iii) third hypothesis of RH mapping might not be entirely correct.

Keywords: Non homologous end joining, Physical mapping, Gamma radiation, Deletion mutant, Chromatin, Wheat chromosome 3B, Radiation hybrid

\footnotetext{
* Correspondence: S.Kianian@NDSU.edu

${ }^{\dagger}$ Equal contributors

'Department of Plant Sciences, North Dakota State University, Fargo, ND 58102, USA

Full list of author information is available at the end of the article
} 


\section{Background}

Genetic mapping has been the foundation of molecular analysis in plants and animals for nearly a century, since the publication of the first map by Sturtevant in 1913 [1]. This widely successful approach relies on recombination to separate and order marker loci. In many plant species, including wheat (Triticum aestivum L.), recombination events are not evenly distributed along the length of the chromosomes [2-7]. Recombination hot-spots, sites with high recombination rates, are interspersed with recombination cold-spots. In addition, in species with large genomes, such as wheat, barley, or maize, recombination frequency tends to decrease with increased proximity to the centromere $[5,7]$, being close to zero at the centromere and its surroundings. It is estimated that about one-fourth to onethird of the $\sim 17 \mathrm{~Gb}$ wheat genome [8] accounts for less than $1 \%$ of the total recombination $[3,5,9]$. Initial studies hypothesized that these recombination poor regions were nothing more than "junk" DNA [10,11], only to discover that over $30 \%$ of wheat genes exist within this space [5]. Limited recombination makes these genes virtually inaccessible to genetic mapping. Similarly, the use of genetic maps as scaffolds to orient physical maps (such as ordered BAC contigs) provides only limited information for these recombination poor regions.

Radiation hybrid ( $\mathrm{RH}$ ) mapping is a method that was originally proposed as an alternative to the use of recombination for mapping marker loci $[12,13]$. In $\mathrm{RH}$ mapping, high dosages of radiation are used to generate random double strand breaks (DSBs) across the genome. The DSBs are then recognized and fixed by one of two main repair mechanisms: homology-directed repair (HR) or non-homologus end-joining (NHEJ), also known as illegitimate recombination [14-17]. Both of these mechanisms are highly conserved in eukaryotes. NHEJ, an error prone mechanism, is considered the prevailing choice of somatic DSB repair in higher eukaryotes [16]. In the last two decades, a number of proteins involved in the NHEJ repair mechanism have been identified [15,16,18,19]. Also, a model has been proposed to explain their interaction and functionality. In brief, presence of DNA broken ends is sensed through the ATM (Ataxia Telangiectasia Mutated) signaling pathway. The $K u$ protein complex is then recruited to the damaged site with the function of protecting the DSBs from further degradation. The $K u$ complex becomes anchored at the break site and is then used as a docking point by DNA phosphokinases, which directly or indirectly create protein bridges to pull the two broken ends together, and finally re-join them by a DNA ligase $[16,18,19]$. When the broken ends are re-joined, the nucleotides located within the adjacent DSBs are lost. The loss mainly involves a small number of nucleotides, but deletions of larger size are not uncommon $[14,16,17]$.
Radiation hybrid mapping exploits the formation of DNA deletions to generate a binary polymorphism (1-retention vs. 0-deletion) which is then used to identify the correct marker order by their simultaneous codeletion or co-retention [12]. While the molecular components of the NHEJ mechanism of repair have been partially or entirely identified, its precise activity in live organisms requires further investigations. In this regard, viable $\mathrm{RH}$ plant populations might represent a novel and useful tool.

During the last two decades, $\mathrm{RH}$ mapping has played an important role in mapping and genome assembly of a number of organisms, including humans and other animals [20-29]. However, only a few preliminary studies have been reported in crop plants, such as maize (Zea mays L.) [30,31], barley (Hordeum vulgare L.) [32], cotton (Gossypium hirsutum L.) [33] and wheat [34-37]. In an effort to sequence the bread wheat chromosome $3 \mathrm{~B}$, a partial physical map covering $82 \%$ of the estimated $993 \mathrm{Mb}$ size of the chromosome was recently published [36]. In that study, RH mapping was tested as a mean to provide good quality scaffolding for physical mapping. Here, we present an extension of that work, with the development of a high density $\mathrm{RH}$ map of chromosome $3 \mathrm{~B}$ to align bacterial artificial chromosome (BAC) contigs. This is an unprecedented opportunity in plants to examine the physical distribution of radiation mediated deletions at a very refined level. Furthermore, this map was employed to assess what are commonly considered the three major advantages of $\mathrm{RH}$ mapping: $i$ ) high map resolution, $\mathrm{ii}$ ) precise conversion of centi Rays (cR, map unit of $\mathrm{RH}$ ) distances to physical distances, and iii) independence from the patterns observed for meiotic recombination events. Surprisingly, the data presented here support only the first two hypotheses, while a strong correlation was identified between the action of the DNA breakage/repair mechanism and the frequency of meiotic recombination events. This result suggests that the state of chromatin may influence the DNA break formation and repair mechanism in a similar way as it influences recombination events.

\section{Results}

\section{A dense and precise 3B-RH map}

In plants, in vivo $\mathrm{RH}$ panels can be generated by simple gamma irradiation of seeds, followed by artificial crosspollination of adult mutant lines. A RH panel for chromosome $3 \mathrm{~B}$ was generated by gamma irradiating seeds of a normal durum line containing chromosome 3B (AABB, $\left.2 \mathrm{n}=2 \mathrm{x}=28: 13 "+3 \mathrm{~B}^{\prime \prime}\right)$ at 350 Gray (Gy) and crossing it to an aneuploid line that lacks this chromosome (13" $\left.+3 D^{\prime \prime}\right)$. A total of $184 \mathrm{RH}_{1}$ lines were developed, and $92 \mathrm{RH}_{1}$ lines were selected on the basis of genotyping data from 84 Insertion Site Based Polymorphism (ISBP, labeled cfp) 
marker loci [36]. The selected sub-population is composed of 70 lines with deletions of various sizes (retention frequency 0.500-0.999), nine lacked the entire chromosome (retention frequency $<0.020$ ), and 13 retained the whole chromosome (retention frequency of 1.000) (Figure 1). The average retention frequency of this selected population was 0.89 . Based on past experience, this small sample is a good representation of any larger $\mathrm{RH}$ population [3436]. Locations of radiation-induced breaks on chromosome 3B were determined employing 541 markers, which include 96 ISBP, 19 Simple Sequence Repeats (SSRs; labeled barc or wmc) and 426 Diversity Array Technology (DArT; labeled wpt or tpt) markers. For 128 of these markers (115 PCR-based and 13 DArTs), the chromosomal location $[38,39]$ and the bacterial artificial chromosome (BAC) contig of appurtenance were known (available at http://urgi. versailles.inra.fr/cgibin/gbrowse/wheat_FPC_pub/). These markers were defined as 'anchor markers'. The marker information was used to construct an iterative framework map of LOD 10 using a modified version of the Carthagene software package [40]; for details on the mapping algorithm see Additional file 1. The final map (3B-RH) spans $1871.9 \mathrm{cR}$, as defined by 202 unique loci (Figure 2). Assuming even distribution of markers along the chromosome, the overall marker density is one marker every $3.5 \mathrm{cR}$, or approximately $1.9 \mathrm{Mb}$ based on the $993 \mathrm{Mb}$ size of chromosome 3B [8]. Quality of the RH map was tested by comparison with two previously published genetic maps $[36,41]$. This examination revealed better conservation of marker loci order between the 3B-RH iterative map and Paux et al. [36] map than between the two genetic maps (Additional file 1 Figure S2). Further confirmation of the strength of this approach was provided by the marker wPt-0223 mapped on the 3B-RH map at position $414.8 \mathrm{cR}$, in between anchor markers cfp5042 and cfp5031, which are at positions $313.1 \mathrm{cR}$ and $419.2 \mathrm{cR}$,

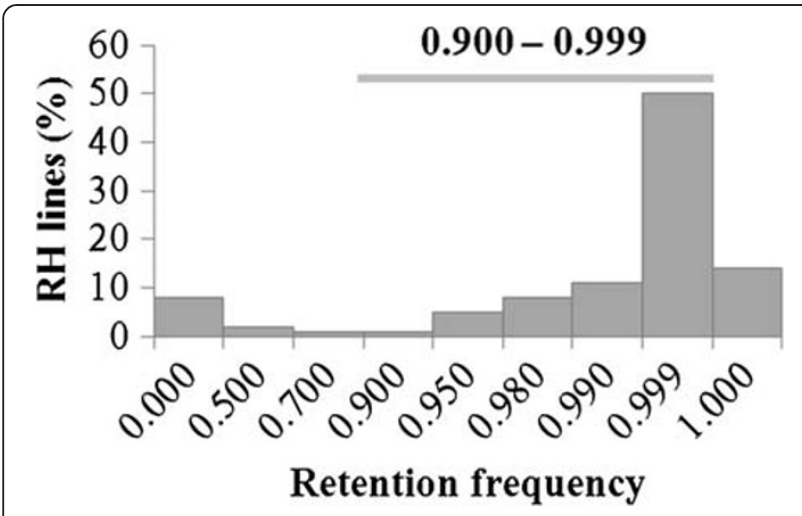

Figure 1 Distribution of marker retention frequencies. The frequencies were calculated from a population of 92 radiation hybrid lines specifically created for chromosome $3 \mathrm{~B}$ of wheat and are based on 541 marker analysis. respectively. Marker wPt-0223 was mapped into contig 954, which has been entirely sequenced [42]. The two anchor markers cfp5042 and cfp5031 are located at $1,103,689$ bp and 1,640,531 bp on this contig, respectively. The sequence of wPt-0223 was used to map this locus in silico at position 2,170,833 bp (i.e. $0.53 \mathrm{Mb}$ proximal of marker cfp5031), just outside the interval predicted in 3BRH. Assuming $100 \%$ to be the error of placing a locus an entire chromosome length away (993 Mb) from its correct physical position, error for the 3B-RH map was calculated $(0.53 \mathrm{Mb} / 993 \mathrm{Mb})$ to be as low as $0.05 \%$. This is a relatively small error considering that only 92 lines were used for the analysis.

\section{$\mathrm{RH}$ map resolution}

Map resolution is defined as the minimum physical distance between two marker loci needed to map them separately. It is calculated as the ratio between physical and map distances (i.e. $\mathrm{Mb}$ divided by $\mathrm{cR}$ or $\mathrm{cM}$ ). Smaller values indicate better resolution. Radiation hybrid maps are expected to provide higher map resolutions than genetic maps, and also a better estimate of the actual physical distance between mapped loci [43]. To verify these two hypotheses, the resolution was estimated at three physical levels: $i$ ) the whole chromosome (993 Mb), ii) chromosome sub-portions, defined as cytogenetic deletion bins (4 Mb to $208 \mathrm{Mb}$; Table 1 ), and iii) within BAC contigs (0.1 Mb to $3.0 \mathrm{Mb}$; Table 2). Cytogenetic deletion bins (hereafter referred to as 'bins') are physical segments of wheat chromosomes identified by cytogenetic lines carrying a terminal deletion of a specific chromosome fragment [44]. The physical sizes of these bins have been estimated through a combination of molecular and cytogenetic studies. These bins are commonly identified by the chromosome number (3B), the chromosome arm ( $\mathrm{S}$ or $\mathrm{L})$, and the percentage of the specific arm that is identified (i.e. $0.63-1.00$, from $63 \%$ of the arm till the end, 100\%); for simplicity, we report the bin full name in Table 1, and we only use an abbreviated identifier in the text. BAC contigs were generated by fingerprinting large libraries of clones, and their physical size is an estimate ([36]; Table 2). The resolution was calculated for both maps, genetic and $\mathrm{RH}$, for the first two levels, but BAC contig analysis was reserved only for $3 \mathrm{~B}-\mathrm{RH}$.

In 3B-RH map, the bin locations were known for 115 anchor markers, and this information was used to extrapolate the locations of the non-anchored markers. The largest portion of 3B-RH map is contained within two bins (3BS8 and 3BL7) accounting for 55\% of the total map size, but only for $25 \%$ of the physical size of chromosome 3B (Table 1 and Figure 2). Assuming complete coverage of the chromosome, and considering the 3B physical size of $993 \mathrm{Mb}$ [8], the 3B-RH map 


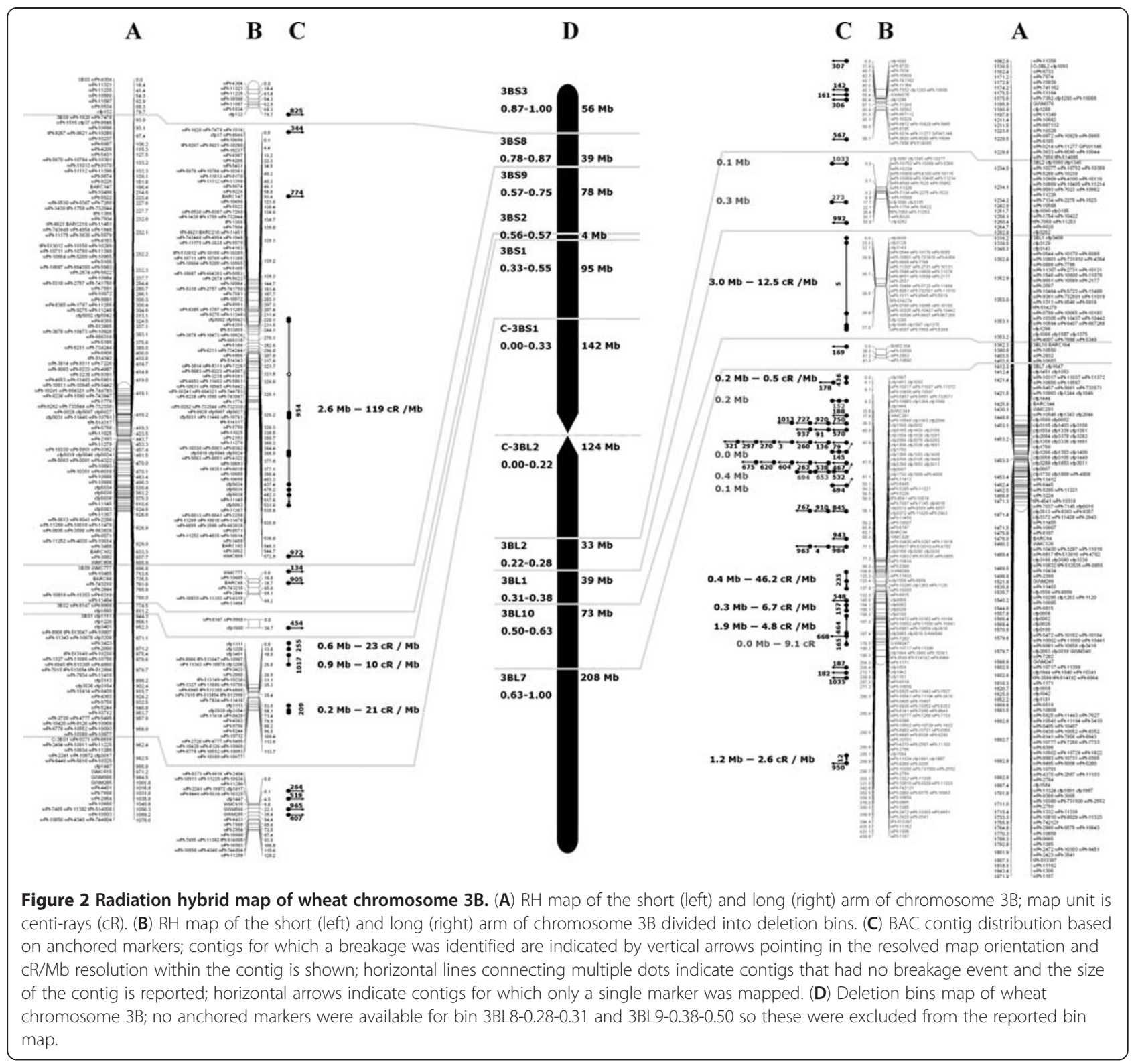

resolution averaged $0.53 \mathrm{Mb} \mathrm{cR}^{-1}$, ranging from $0.1 \mathrm{Mb}$ $\mathrm{CR}^{-1}$ for bin 3BS8 and 3BS2 to $1.8 \mathrm{Mb} \mathrm{cR}^{-1}$ for $3 \mathrm{BL} 10$ (Table 1$)$. The two centromeric bins exhibited very similar resolutions, $1.2 \mathrm{Mb} \mathrm{cR}^{-1}$ and $1.3 \mathrm{Mb} \mathrm{cR}^{-1}$ in $\mathrm{C}-3 \mathrm{BS} 1$ and C-3BL2, respectively (Table 1). Chromosome-wise, the RH map resolution deviated less than five-fold from the calculated average. In comparison, the resolution calculated by Saintenac et al. [7] for their genetic map of chromosome 3B was $5.5 \mathrm{Mb} \mathrm{cM}^{-1}, 10.5$ fold lower than the resolution of the 3B-RH map, and deviated along the chromosome up to 30 fold (1.2 and 167.1 $\mathrm{Mb} \mathrm{cM}^{-1}$ ) from the average (Table 1).

The resolution of the 3B-RH map reached its minimum in bin 3BL10 at $1.8 \mathrm{Mb} \mathrm{cR}^{-1}$. Based on this value, the small population of $92 \mathrm{RH}_{1}$ lines used should have the mapping potential to uniquely order any BAC contig with size $>1.8 \mathrm{Mb}$. To test this hypothesis, markers anchored to 72 BAC contigs (Table 2 and Figure 2), 15 from the short arm and 57 from the long arm, mainly belonging to the bin 3BL7 (45 contigs), were analyzed. A contig can be assigned to a specific chromosomal position with the help of a single marker; however, two or more mapped markers are required to orient a contig. For 17 of 72 contigs two or more markers were available, and nine of these could be uniquely oriented (Table 2). The physical distance between the markers used to orient the contigs ranged from $3.0 \mathrm{Mb}$ for contig 5, to $0.0 \mathrm{Mb}$ (meaning that the markers are at a distance too small to be dissected by BAC fingerprinting but are not necessarily at the same locus, see [42]) for contig 145 . 


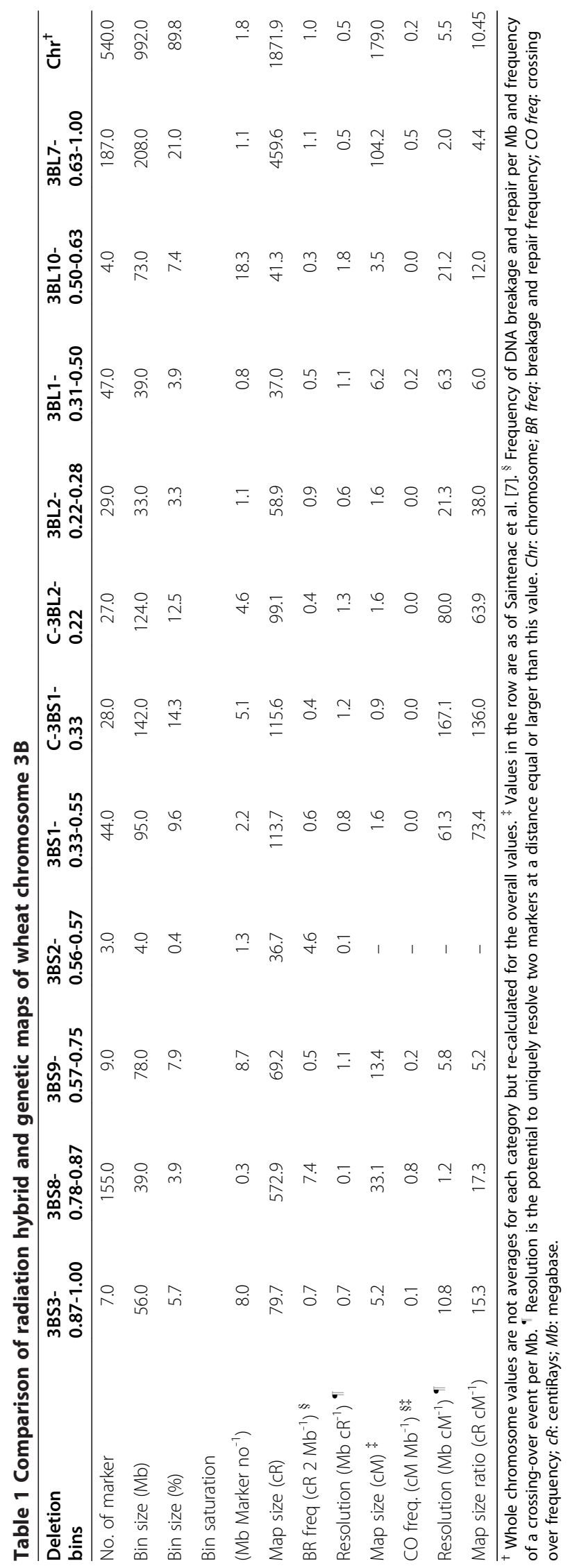


Table 2 BAC contigs of known physical size mapped on radiation hybrid map of wheat chromosome 3B

\begin{tabular}{|c|c|c|c|c|c|}
\hline Contig ID & $\begin{array}{l}\text { Size } \\
(\mathrm{Mb})\end{array}$ & $\begin{array}{l}\text { Size } \\
\text { (cR) }\end{array}$ & Markers (count) & $\begin{array}{l}\text { Resolution } \\
\left(\mathrm{Mb} \mathrm{cR}^{-1}\right)\end{array}$ & Deletion Bin \\
\hline Ctg0954 & 2.6 & 311.5 & 12 & 0.01 & $3 \mathrm{BS} 8-0.78-0.87$ \\
\hline Ctg0209 & 0.2 & 4.2 & 3 & 0.04 & $3 B S 1-0.33-0.55$ \\
\hline Ctg0255 & 0.6 & 13.8 & 2 & 0.04 & $3 B S 1-0.33-0.55$ \\
\hline Ctg1017 & 0.9 & 8.8 & 2 & 0.10 & $3 B S 1-0.33-0.55$ \\
\hline Ctg0005 & 3.0 & 37.0 & 6 & 0.08 & 3BL 1-0.31-0.38 \\
\hline Ctg0235 & 0.4 & 18.3 & 3 & 0.02 & 3BL7-0.63-1.00 \\
\hline Ctg0464 & 1.9 & 9.1 & 3 & 0.20 & 3BL7-0.63-1.00 \\
\hline Ctg0012 & 1.2 & 4.5 & 2 & 0.26 & 3BL7-0.63-1.00 \\
\hline Ctg0157 & 0.3 & 2.0 & 2 & 0.14 & $3 B\llcorner 7-0.63-1.00$ \\
\hline Sub-total & 10.9 & 418.3 & 35 & ${ }^{\dagger} 0.09$ & \\
\hline Ctg0273 & 0.3 & 0.0 & 2 & & $3 B L 2-0.22-0.28$ \\
\hline Ctg1033 & 0.1 & 0.0 & 2 & & $3 B L 2-0.22-0.28$ \\
\hline Ctg0145 & 0.0 & 0.0 & 3 & & $3 B L 7-0.63-1.00$ \\
\hline Ctg0152 & 0.2 & 0.0 & 3 & & 3BL7-0.63-1.00 \\
\hline Ctg0436 & 0.2 & 0.0 & 2 & & $3 B L 7-0.63-1.00$ \\
\hline Ctg0532 & 0.2 & 0.0 & 2 & & $3 B L 7-0.63-1.00$ \\
\hline Ctg0653 & 0.4 & 0.0 & 2 & & $3 B L 7-0.63-1.00$ \\
\hline Ctg0694 & 0.1 & 0.0 & 2 & & 3BL7-0.63-1.00 \\
\hline Total & 12.5 & & 52 & & \\
\hline
\end{tabular}

The first nine contigs could be oriented, the remaining eight could not be oriented.

${ }^{\dagger}$ Average.

As expected, the eight contigs that could not be oriented contained markers spaced by distances $<1.8 \mathrm{Mb}$, ranging from $0.4 \mathrm{Mb}$ to $0.0 \mathrm{Mb}$. Map resolution within contigs were also calculated, ranging from $0.01 \mathrm{Mb} \mathrm{cR}^{-1}$ for contig 954, to $0.26 \mathrm{Mb} \mathrm{cR}^{-1}$ for contig 12 (Table 2) and averaging $0.09 \mathrm{Mb} \mathrm{cR}^{-1}$ for the whole chromosome.

\section{Sizes of gamma ray induced chromosome deletions in the} 3B-RH panel

A single radiation-induced deletion was defined by a set of flanking markers detecting an uninterrupted deletion smaller than a whole chromosome arm. Eight of the 92 lines had continuous deletions larger than a chromosome arm, retaining only a small portion of chromosome $3 \mathrm{~B}$, probably through translocation to a different chromosome. One line apparently lost the entire chromosome. The loss of an entire chromosome can be due to large rearrangements or improper chromosome sorting at meiosis, possibly caused by excessive deletions or removal of critical segments, such as the centromere. Thirteen putative $\mathrm{RH}$ lines did not show any deletions (Figure 1). These 22 lines were not considered when calculating the deletion size. In the absence of a fully sequenced genome, the deletion size was measured in map units $(\mathrm{cR})$ and then converted into $\mathrm{Mb}$, based on the conversion ratio calculated for each bin (i.e. resolution, Table 1).

The largest deletion identified spans $120.2 \mathrm{cR}$, representing the loss of the entire bin C-3BS1 equal to 144 $\mathrm{Mb}$, while the smallest deletion stretches $13.1 \mathrm{cR}$ of bin 3BS8, accounting for $1.3 \mathrm{Mb}$ in size. Deletions of smaller size are also possible [14] but their identification would require a more targeted approach than the one employed here. The average deletion size across chromosome 3B was 26.4 Mb, ranging from 5.9 Mb of bin 3BS8 to $71.4 \mathrm{Mb}$ of bin C-3BL2 (Figure 3). On average, each of the 70 informative lines carried 2.8 deletions, ranging from one to thirteen (Figure 2). There is an inverse correlation $(r=-0.64, p=0.05)$ between the number of deletions and their relative size, with the centromeric regions typically having fewer but larger deletions and the telomeric regions having smaller and more frequent deletions.

Also, the distribution of deletion frequency (defined as how frequently a given marker locus is lost in a population) across the $\mathrm{RH}-3 \mathrm{~B}$ population was investigated in an attempt to identify any chromosomal region which is preferentially deleted or retained (Figure 4, Additional file 1 Figure S3). The average deletion frequency was $13 \%$, reaching a maximum of $15 \%$ in $\mathrm{C}-3 \mathrm{BS} 1$ and a minimum of $12 \%$ in $3 \mathrm{BL} 1$. Overall the deletion frequency 


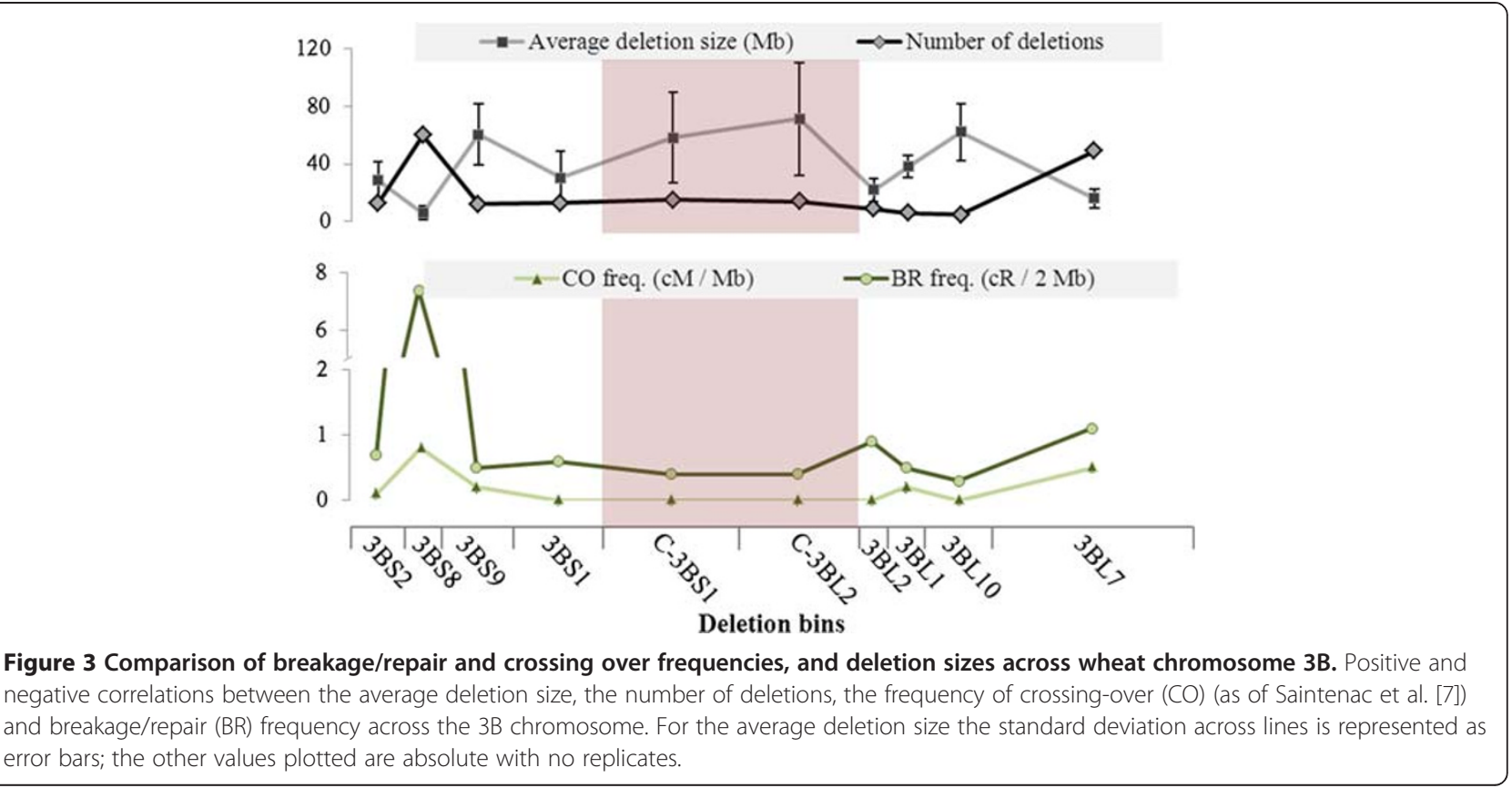

was evenly distributed and no significant difference was observed among the bins. Apparently, the vicinity to chromosomal landmarks such as the centromere or telomeres does not influence the frequency at which a given locus is lost, but rather the size or number of deletions that are created.

\section{Distribution of DNA break/repair events show correlation to the frequency of crossing-over}

The $\mathrm{cR}$ unit measures the frequency of co-retention of two marker loci (i.e, one $\mathrm{cR}$ is one difference of the state (deleted $v s$. retained) between two adjacent loci observed in every 100 lines screened). Similarly, one cM indicates one recombination event between two loci in 100 lines. Deletion of one locus is likely the result of two DSBs, one distal and one proximal to the lost marker locus. Therefore, the number of deletions between two markers in 100 lines can be obtained by dividing the $\mathrm{cR}$ distance separating them by two. A DNA deletion in $\mathrm{RH}$ is the consequence of a radiation-mediated breakage, which is then repaired by the DNA-damage repair mechanism. Hence, when dividing half of the $\mathrm{cR}$ distance between two markers by the physical size that separates them, we are measuring the frequency at which radiationmediated DSBs are formed and then repaired, most likely through NHEJ. This frequency (called break/repair (BR) frequency; Table 2) was calculated and expressed as the number of breakage/repair events (i.e. $\mathrm{cR} / 2$ ) per $\mathrm{Mb}$. For instance, a BR frequency of $1 \mathrm{cR} / 2 \mathrm{Mb}^{-1}$ would indicate that in a specific interval two breakage/repair events occurred on average every $1 \mathrm{Mb}$, while a value of $10 \mathrm{cR} /$ $2 \mathrm{Mb}^{-1}$ would suggest $20 \mathrm{BR}$ events every Mb. Similarly, by dividing $\mathrm{cM}$ by the physical size of the interval, we are measuring the average physical distance that separated crossing-over (CO frequency; [7]).

Crossing-over frequencies in wheat are known to be unevenly distributed across the chromosome, and generally decrease with proximity to the centromere [7]. The

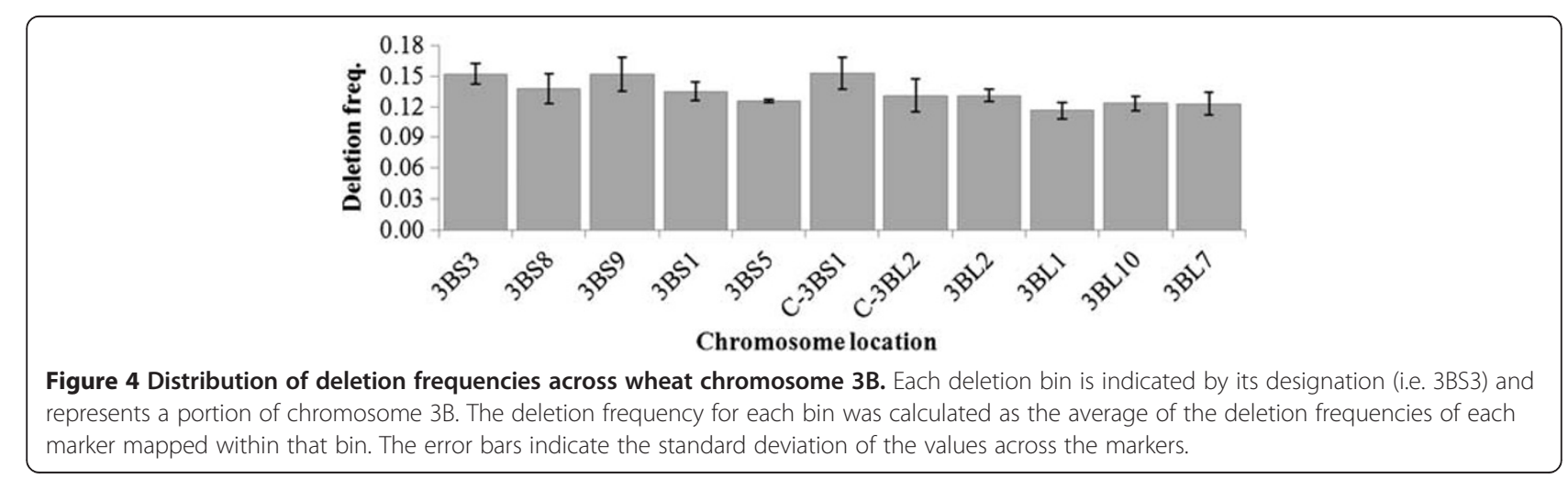


relative distance from the centromere does not entirely explain the distribution of $\mathrm{CO}$ events, still we confirmed a positive correlation $(\mathrm{r}=0.604, \mathrm{p}=0.05)$ between the frequency of $\mathrm{CO}$ and the relative distance from the centromere. The same analysis did not return a significant interaction between the BR frequency and the distance from centromere $(r=0.292)$, further confirming that the proximity to chromosomal landmarks by itself does not influence the frequency of DNA breakage and repair. However, bin 3BS8 exhibited the highest BR frequency $\left(7.4 \mathrm{cR} / 2 \mathrm{Mb}^{-1}, 7.7\right.$-fold higher than the chromosome average) and $\mathrm{CO}$ frequency $\left(0.8 \mathrm{cM} \mathrm{Mb}^{-1}\right.$, 4-fold higher than average). Bin 3BL10 exhibited one of the lowest $\mathrm{CO}$ frequency $\left(0.05 \mathrm{cM} \mathrm{Mb}^{-1}\right.$, 4-fold below average), and also the lowest BR frequency $\left(0.3 \mathrm{cR} / 2 \mathrm{Mb}^{-1}\right.$, 3.6-fold lower than the chromosome average). The similarity between these values prompted us to compute chromosome-wide correlation between the BR frequencies and the $\mathrm{CO}$ frequencies (Figure 3). A correlation coefficient $\quad r=0.879 \quad(p=0.01)$ was obtained when considering the ten bins for which information on both frequencies was available. Bin 3BS2 was excluded from the analysis due to lack of $\mathrm{CO}$ frequency data. This significant correlation indicates that the $\mathrm{CO}$ and $\mathrm{BR}$ frequencies are not independent values (Figure 3). Furthermore, the total number and average size of radiation-mediated deletions in each deletion bin was calculated, confirming that both $\mathrm{CO}$ and BR frequencies are positively correlated $(p=0.01)$ with the number of deletions, but only weakly inversely correlated with the average deletion size $(p=0.06)$ (Figure 3$)$. No significant correlation was observed between $\mathrm{CO}$, BR frequencies and markers deletion frequencies. To avoid confusion, we would like to emphasize that BR frequency and deletion frequency do not measure the same biological effect. The BR frequency value estimates the activity of the DNA repair mechanism, while the deletion frequency measures just the number of times that a given locus or a region is damaged by radiation.

\section{Discussion}

In this study, a population of $92 \mathrm{RH}_{1}$ lines was analyzed using a novel iterative framework mapping algorithm (Additional file 1) to generate a dense RH map of wheat chromosome 3B. The map quality tests indicated a small map error $(0.05 \%)$. Hence, it was concluded that the method employed for mapping did not generate any perceivable bias, and downstream analyses should not be skewed by the anchor marker mapping approach.

Is $\mathrm{RH}$ mapping resolution higher and more uniform than the resolution of genetic mapping? To answer this question, the 3B-RH map was compared to the high quality genetic map of chromosome $3 \mathrm{~B}$ published by Saintenac et al. [7]. The 3B-RH panel provided on average a 10.5 fold higher overall resolution than the genetic map, reaching a maximum of 136 -fold better resolution at the centromere, where recombination is most scarce. We believe that this is sufficient evidence to conclude that $\mathrm{RH}$ mapping indeed provides higher resolution than genetic mapping. The average resolution is often calculated for genetic maps, but the uneven distribution of recombination along a chromosome can result in up to 30 -fold variation between telomeric and centromeric regions (1.2 to $167.1 \mathrm{Mb} \mathrm{cM}^{-1}$; Table 1). For this reason, the resolution value calculated for genetic maps is not a reliable measure of the actual physical distance separating the mapped loci. To investigate if RH maps would provide a more uniform resolution across the chromosome, the average resolution for the entire chromosome was compared with the resolution for each chromosomal region. The average resolution, calculated as the total physical size of the chromosome divided by the total map length, was $0.53 \mathrm{Mb} \mathrm{cR}^{-1}$ and a maximum of five-fold deviation from this value $\left(0.1\right.$ and $\left.1.8 \mathrm{Mb} \mathrm{CR}^{-1}\right)$ along the chromosome was observed. Thus $\mathrm{RH}$ mapping resolution is six times more uniform than genetic mapping resolution. The resolution within BAC contigs for this map was also assessed. In this case, resolution fluctuated more dramatically, ranging from $0.26 \mathrm{Mb} \mathrm{cR}^{-1}$ to $0.01 \mathrm{Mb} \mathrm{cR}^{-1}$ a 53-fold increase from the chromosomewide average, and averaged at $0.09 \mathrm{Mb} \mathrm{cR}^{-1}$ (six-fold increase). This large fluctuation is probably the result of the non-random selection of $\mathrm{RH}$ lines identified at the beginning of the study. In fact, the subset of 92 lines was specifically selected for their quality of mapresolving 84 markers of the 109 employed to measure the BAC contig resolution. It is then not surprising that they provide a much higher resolution exactly for those markers that were used in the initial selection.

Overall, the lowest resolution observed for any chromosome region in this study was $1.8 \mathrm{Mb} \mathrm{cR}^{-1}$. This indicates the ability of our small $\mathrm{RH}$ population to unequivocally orient any BAC contig of size larger than 1.8 Mb. Only eight BAC contigs could not be uniquely oriented in this study, the largest of which was only $0.4 \mathrm{Mb}$ in size. Such high resolution has been observed in many human and animal radiation hybrid maps before $[21,27,29]$, but among plant studies reported to date only a resolution of $\sim 0.2 \mathrm{Mb}$ calculated on the number of obligate breaks for chromosome 1D of wheat [35] is close to the high resolution presented here.

\section{The chromatin state affects the DNA break/repair mechanism}

RH studies rely on the random formation of deletions for mapping. Given the theoretical absence of molecular bias, the RH mapping approach has been thought 
to provide a true physical representation of chromosomes $[13,35,45]$. In contrast, genetic maps are not precise physical representation of the genome because they rely on recombination events that may not be evenly distributed $[7,13,35,45]$. The biased distribution of crossing-over events is associated with the specific requirements of the recombination machinery. In yeast and mouse, meiotic DSBs that initiate recombination are predominantly formed in open chromatin sites marked by trimethylation of lysine at position 4 in the H3 histone [46-48]. Little is known about patterns of meiotic DSB formation in plants [49], but they are likely similar to those in yeast and mammals, i.e. fewer DSBs are formed in the more densely packed chromatin regions [50]. Open chromatin regions should be more common in the distal regions of wheat chromosomes [7].

The data presented here confirms that the frequency of $\mathrm{CO}$ events are partially dependent on the relative distance from the centromere $(p=0.05)$ but fails to identify a similar correlation for BR frequency. This lack of correlation supports the hypothesis that $\mathrm{RH}$ maps are indeed true physical representations of chromosomes, and that the formation of deletions are random events independent of chromosome landmarks. However, it must be kept in mind that $\mathrm{CO}$ happens at meiosis, when chromosome are highly compacted, while BR occurs in somatic cells mostly during mitotic interphase, when chromosome landmarks are hard to observe. On the other hand, data presented here show dependent distribution between $\mathrm{CO}$ and BR events, suggesting a similar preference for specific chromosomal regions for both mechanisms. In literature, three plant studies have reported strong correlations between meiotic CO frequencies and somatic DNA break and repair processes. Liu et al. [51] showed that distribution of insertions of the $M u$ transposon in maize correlates with the distribution of recombination events across the genome. Similarly, Choulet et al. [42] identified correlation between transposable element (TE) distribution and disruption of gene order conservation, which is accelerated by COs. The third study demonstrated a correlation between TE distribution and modification of gene order, as well as a correlation between nonsyntenic gene order and the CO frequency [52]. A common causative factor that explains the observed correlations is the dependence of all three processes, TE insertion, gene order disruption and $\mathrm{CO}$ formation, on formation of DSBs. Based on these reports and data presented here, one can postulate that the correlation between $\mathrm{CO}$ frequency and BR frequency can also be explained by the dependence on DSBs formation in both processes, and their consequent dependence on the chromatin state.

\section{A working hypothesis: how does the chromatin state affects the DNA-damage/repair mechanism?}

Assuming that the breakage/repair mechanism has a preference for open chromatin regions, it is intriguing to hypothesize on how these regions specifically influence this process. There are two levels at which the state of chromatin could influence formation of chromosomal deletions: $i$ ) regions of compact chromatin could be more resistant to radiation damage; and/or $i$ ) the repair mechanism requires open chromatin regions to perform its activity. If the first hypothesis is correct, we should observe a reduction in the number of deletions in those regions that are particularly heterochromatic, such as the peri- and centromeric regions. The data presented in Figure 4 (and extended in Additional file 1 Figure S3 in SI) show no significant difference in the frequency at which deletions forms in the telomere or centromere of chromosome 3B. This would suggest that chromatin compactness by itself is not a sufficient shield to prevent DNA damage. A similar conclusion was also reached for yeast [53] and humans [54], leaving our first hypothesis short of supporting evidences. On the other hand, it leaves open the possibility that the chromatin state directly influences the repair mechanism, possibly preventing the formation of non-radiation-mediated DSBs, necessary to complete the repair. Goodarzi et al. [55] demonstrated that in human cells the repair complex is unable to adequately access or manipulate radiationmediated breaks occurring in regions of compact chromatin. Hence, if radiation-mediated breaks happen independently from the chromatin state, but less condensed chromatin is necessary for the DNA repair mechanism to properly operate, logic dictates that in tightly compacted chromosomal regions larger and less frequent deletions are expected, while in more open regions the number of deletions would increase and their size diminishes. That is precisely what we observed for chromosome 3B (Figure 3). Thus this data supports in vivo the hypothesis that "higher order chromatin architecture exerts just as profound an influence on DNA repair as it does on nuclear processes such as transcription and replication" [54].

\section{Conclusion}

Radiation hybrid mapping is an effective approach to map all markers (monomorphic or otherwise) in wheat and other organisms. High levels of mapping resolution can be achieved with relatively small populations. Since its first application 37 years ago [12] RH mapping was believed an approach totally independent from patterns of recombination. Here, for the first time, data have been collected that suggest otherwise, indicating that $\mathrm{RH}$ mapping relies on higher order chromatin structure similar to recombination hot-spots observed in genetic 
mapping. However, the 3B-RH map generated still offered a resolution eleven fold higher than a comparable genetic map and a fairly consistent physical to $\mathrm{cR}$ conversion across the entire chromosome, making this approach the most dependable for the scaffold assembly of genome sequencing initiatives. Moreover, in plants $\mathrm{RH}$ lines can be produced entirely in vivo, providing a unique tool to study the effect of radiation in living organisms. New insights have been gathered in the past few years on possible interactions between the state of chromatin and various DNA break-repair processes, such as those involved in $\mathrm{CO}$ event formation, DNA repair, TE insertion, and synteny disruption. We presented here a working hypothesis to explain how the chromatin state could affect the DNA repair mechanism, together with the biological material to further investigate this hypothesis. Specifically targeted cytogenetic studies employing $\mathrm{RH}$ lines are likely to provide the evidences necessary to shed light on the precise effect of chromatin on the DNA break-repair mechanism.

\section{Methods}

\section{RH mapping population}

The 3B-RH panel was generated as described in Paux et al... [36] by crossing the durum wheat Triticum durum L. var. 'Langdon' (LDN) after irradiation at 350 Gy of gamma ray to the aneuploid 'Langdon' 3D(3B) (LDN 3D (3B)). $\mathrm{RH}_{1}$ seeds were planted under controlled greenhouse conditions and DNA was extracted from leaves of four weeks old plants as described earlier [34]. Nonirradiated double monosomic $\left(13^{\prime \prime}+3 B^{\prime}+3 D^{\prime}\right) F_{1}$ lines were also generated and employed as experimental controls. All DNA samples were equilibrated to concentrations of $50 \mathrm{ng}$ per $\mu \mathrm{l}$. A total of $184 \mathrm{RH}_{1}$ lines were initially employed in this study, but only 92 selected lines were fully genotyped.

\section{Molecular analysis}

Genotyping was conducted with three classes of markers: cfp are PCR-based ISBP [56,57]; barc, gwm, and gpw are PCR-based SSR (http://wheat.pw.usda.gov/GG2/ index.shtml); wPt and tPt are DArT markers (Canberra, AU) [41]. To guarantee chromosome $3 \mathrm{~B}$ specificity, all markers were tested for positive amplification (ISBP and SSR) or hybridization (DArT) of the double monosomic $\mathrm{F}_{1}$ control line, and no-amplification / hybridization of LDN 3D(3B). In order to distinguish PCR failure from deletion-detection, all the markers amplifying a single $3 \mathrm{~B}$ specific band were multiplexed with the control marker DEASY (Duplexing EASY) amplifying 164 bp of a chloroplastic ATP syntase alpha subunit [GebBank: M16842]. All PCR protocols have been described previously $[36,39,56,57]$. Ninety-two samples plus four experimental controls were genotyped in duplicate using the
3B specific DArT array following the protocol described in Wenzl et al. [41]. The deletion frequency is calculated as the number of loci with deletion divided the total number of loci genotyped, while the retention frequency is one minus the deletion frequency. The $3 \mathrm{~B}$ genetic map resolution and $\mathrm{CO}$ frequency was calculated in Saintenac et al. [7]. The Carthagene mapping software v1.2.2 [40] was modified and used to generate a RH map of the entire $3 \mathrm{~B}$ chromosome. Details on the superimposed modifications are available in Additional file 1.

\section{Statistical analysis}

All correlation analyses were performed using the SAS 9.3 environment (SAS Institute, Cary, NC) and the correlation significance was determined on the basis of the Pearson product-moment correlation coefficient for a two-tail test with $\mathrm{N}-2$ degrees of freedom, where $\mathrm{N}$ is the number of deletion bins considered [58].

\section{Additional file}

Additional file 1: Supplementary text, tables and figures. The file contains supplementary text, Table S1, Figure S1, S2 and S3. Suppl. Text describes the rational of radiation hybrid mapping, the algorithm developed to exploit the specific characteristics of this type of mapping and its proof of concept. Table S1 presents the statistical details of the iterative frame work mapping approach applied to the radiation hybrid map of chromosome 3B. Figure S1 shows the superior marker order conservation between $3 \mathrm{~B}$-radiation hybrid $(3 \mathrm{~B}-\mathrm{RH})$ map and the $3 \mathrm{~B}$ genetic map when employing iterative frame work mapping algorithm, instead of a non-iterative approach. Figure $\mathrm{S} 2$ shows how the error in marker order conservation between the $3 \mathrm{~B}-\mathrm{RH}$ map and the $3 \mathrm{~B}$ genetic map is lower than the error that exists between published genetic maps. Figure $\mathrm{S} 3$ shows that marker loci have non significantly different deletion frequencies throughout the $3 \mathrm{~B}$ chromosome $[36,41,59]$.

\section{Abbreviations}

RH: Radiation hybrid; DSB: Double strand break; HR: Homology-directed repair; NHEJ: Non-homologous end-joining; BAC: Bacterial artificial chromosome; CR: centi Rays; Gy: Gray; ISBP: Insertion site based polymorphism; SSR: Simple sequence repeat; DArT: Diversity Array Technology; BR: Break/repair; CO: Crossing over; LDN: 'Langdon'; LDN 3D (3B): 'Langdon' with chromosome 3B substituted by chromosome 3D; DEASY: Duplexing EASY.

\section{Competing interests}

The authors declare that they have no competing interests.

\section{Authors' contributions}

A.Kumar, F.M.B., E.P., M.M. de J., Y.Q.G., C.F., and S.F.K designed research; A.Kumar, F.M.B., M.M. de J. S.K., A.G., V.T. and M.D. performed the research; E.P., E.H., A. Kilian, and C.F. provided access to advanced analytical tools and unpublished data; O.Al-A. and A.M.D. developed iterative framework mapping script; H.S.B., H. S.D., P.K.G., and G.S.R. provided support for student interns A.Kumar, S.K., A.G., and V.T.; F.M.B., A. Kumar, E.P., M.M. de J., W.P.P and E.H. analyzed the data; F.M.B, A.Kumar, E.P.,W.P.P., S.F.K. wrote the paper, M.J.I. and S.F.K. managed the project. All authors read and approved the final manuscript

\section{Acknowledgments}

The authors wish to thank Justin Hegstad and Allen Peckrul for assistance in the development of RH panel and capable technical support throughout the research; Dr. Matthew Hayden (VABC, Melbourne, AUS) for precious 
contributions in designing the DEASY control marker; Dr. Nellye Cubizolles (INRA, Clermont Ferrand, FR) for technical support in the use of cfp markers; Dr. Cyrille Saintenac (INRA, Clermont Ferrand, FR) and his collaborators for making publicly available their excellent work. This work was supported by funding from the National Science Foundation, Plant Genome Research Program (NSF-PGRP) grant No. IOS-0822100 to SFK. Additional support from the NSF-PGRP Developing Country Collaboration aided the assistance of student interns A.Kumar, S.K., A.G., and V.T.; F.M.B was partially supported by Program Master and Back Regione Autonoma della Sardegna and Monsanto Beachell-Borlaug International Scholarship.

\section{Author details}

'Department of Plant Sciences, North Dakota State University, Fargo, ND 58102, USA. ${ }^{2}$ INRA-UBP 1095, Genetics Diversity and Ecophysiology of Cereals, Clermont-Ferrand 63100, France. ${ }^{3}$ Department of Computer Science, North Dakota State University, Fargo, ND 58102, USA. ${ }^{4}$ USDA-ARS, Western Regional Research Center, Albany, CA 94710, USA. ${ }^{5}$ Diversity Arrays Technology Pty Ltd, Yarralumla, ACT 2600, Australia. ${ }^{6}$ Department of Genetics and Plant Breeding, Ch. Charan Singh University, Meerut 25004, India. Department of Crop and Soil Science, Oregon State University, Corvallis, OR 97331, USA. ${ }^{8}$ USDA-ARS, Biosciences Research Laboratory, Fargo, ND 58102, USA. ${ }^{9}$ Akal School of Biotechnology, Eternal University, Baru Sahib 173101, India. ${ }^{10}$ Department of Biotechnology, Indian Institute of Technology, Roorkee 247667, India. ${ }^{11}$ Department of Plant Breeding and Genetics, Cornell University, Ithaca, NY 14853, USA.

Received: 9 May 2012 Accepted: 7 July 2012

Published: 24 July 2012

\section{References}

1. Sturtevant AH: The linear arrangement of six sex-linked factors in Drosophila, as shown by their mode of association. J Exp Zool 1913, 14:43-59.

2. Gill KS, Gill BS, Endo TR: A chromosome region-specific mapping strategy reveals gene-rich telomeric ends in wheat. Chromosoma 1993, 102:374-381.

3. Lukaszewski AJ, Curtis CA: Physical distribution of recombination in Bgenome chromosomes of tetraploid wheat. Theor Appl Genet 1993 86:121-127.

4. Hohmann U, Endo TR, Gill KS, Gill BS: Comparison of genetic and physical maps of group-7 chromosomes fromTriticum aestivumL. Mol Gen Genet 1994. 245:644-653.

5. Erayman M, Sandhu D, Sidhu D, Dilbirligi M, Baenziger PS, Gill KS: Demarcating the gene-rich regions of the wheat genome. Nucleic Acids Res 2004, 32:3546-3565.

6. Mézard C: Meiotic recombination hotspots in plants. Biochem Soc Trans 2006, 34:531-544.

7. Saintenac C, Falque M, Martin OC, Paux E, Feuillet C, Sourdille P: Detailed recombination studies along chromosome $3 B$ provide new insight on crossover distribution in wheat (Triticum aestivumL.). Genetics 2009, 181:393-403.

8. Dolezel J, Simkova H, Kubalakova M, Safar J, Suchankova P, Cihalikova J, Bartos J, Valarik M: Chromosome genomics in the Triticeae. In Genetics and Genomics of the Triticeae. Edited by Feuillet C, Muehlbauer GJ. New York: Springer; 2009:285-316.

9. Akhunov ED, Goodyear AW, Geng S, Qi LL, Echalier B, Gill BS, Miftahudin, Gustafson JP, Lazo G, Chao S, Anderson OD, Linkiewicz AM, Dubcovsky J, La Rota M, Sorrells ME, Zhang D, Nguyen HT, Kalavacharla V, Hossain K, Kianian SF, Peng J, Lapitan NL, Gonzalez-Hernandez JL, Anderson JA, Choi DW, Close TJ, Dilbirligi M, Gill KS, Walker-Simmons MK, Steber C, et al: The organization and rate of evolution of wheat genomes are correlated with recombination rates along chromosome arms. Genome Res 2003, 13:753-763.

10. Ohno S: So much "junk" DNA in our genome. In Evolution of Genetic Systems. Edited by Smith HH. New York: Brookhaven SympBiol, Gorden \& Breach; 1972:366-370.

11. Makalowski W: Not junk after all. Science 2003, 300:1246-1247.

12. Goss $\mathrm{SJ}$, Harris $\mathrm{H}$ : New method for mapping genes in human chromosomes. Nature 1975, 255:680-684.

13. Cox DR, Burmeister M, Price ER, Kim S, Myers RM: Radiation hybrid mapping: a somatic cell genetic method for construction of highresolution maps of mammalian chromosomes. Science 1990, 250:245-250.
14. Britt AB: Molecular genetics of DNA repair in higher plants. Trends Plant Sci 1999, 4:1360-1385.

15. Puchta $\mathrm{H}$ : The repair of double-strand breaks in plants: mechanisms and consequences for genome evolution. J Exp Bot 2005, 56:1-14.

16. Bleuyard JY, Gallego ME, White Cl: Recent advances in understanding of the DNA double-strand break repair machinery of plants. DNA Repair 2006, 5:1-12.

17. Bernstein KA, Rothstein R: At loose ends: resecting a double-strand break. Cell 2009, 137:807-810

18. Lliakis G, Wang H, Perrault AR, Boecker W, Rosidi B, Windhofer F, Wu W, Guan J, Terzoudi G, Pantelias G: Mechanism of DNA double strand break repair and chromosome aberration formation. Cytogenet Genome Res 2004, 104:14-20

19. Xu Y, Price BD: Chromatin dynamics and repair of DNA double strand break. Cell Cycle 2011, 10:261-267.

20. Lander ES, Linton LM, Birren B, Nusbaum C, Zody MC, Baldwin J, Devon K, Dewar K, Doyle M, FitzHugh W, Funke R, Gage D, Harris K, Heaford A, Howland J, Kann L, Lehoczky J, LeVine R, McEwan P, McKernan K, Meldrim J, Mesirov JP, Miranda C, Morris W, Naylor J, Raymond C, Rosetti M, Santos R, Sheridan A, Sougnez $C$, et al: Initial sequencing and analysis of the human genome. Nature 2001, 409:860-921.

21. Olivier M, Aggarwal A, Allen J, Almendras AA, Bajorek ES, Beasley EM, Brady SD, Bushard JM, Bustos VI, Chu A, Chung TR, De Witte A, Denys ME, Dominguez R, Fang NY, Foster BD, Freudenberg RW, Hadley D, Hamilton LR, Jeffrey TJ, Kelly L, Lazzeroni L, Levy MR, Lewis SC, Liu X, Lopez FJ, Louie B, Marquis JP, Martinez RA, Matsuura MK, et al: A high-resolution radiation hybrid map of the human genome draft sequence. Science 2001, 291:1298-1302.

22. Waterston RH, Lindblad-Toh K, Birney E, Rogers J, Abril JF, Agarwal $P$, Agarwala R, Ainscough R, Alexandersson M, An P, et al: Initial sequencing and comparative analysis of the mouse genome. Nature 2002, 420:520-562.

23. Gibbs RA, Weinstock GM, Metzker ML, Muzny DM, Sodergren EJ, Scherer S, Scott G, Steffen D, Worley KC, Burch PE, et al: Genome sequence of the brown Norway rat yields insights into mammalian evolution. Nature 2004, 428:493-521.

24. Lindblad-Toh K, Wade CM, Mikkelsen TS, Karlsson EK, Jaffe DB, Kamal M, Clamp M, Chang JL, Kulbokas EJ 3rd, Zody MC, Mauceli E, Xie X, Breen M, Wayne RK, Ostrander EA, Ponting CP, Galibert F, Smith DR, DeJong PJ, Kirkness E, Alvarez P, Biagi T, Brockman W, Butler J, Chin CW, Cook A, Cuff J, Daly MJ, DeCaprio D, Gnerre S, et al: Genome sequence, comparative analysis and haplotype structure of the domestic dog. Nature 2005, 438:803-819.

25. Karere GM, Froenicke L, Millon L, Womack JE, Lyons LA: A highresolution radiation hybrid map ofrhesus macaquechromosome 5 identifies rearrangements in the genome assembly. Genomics 2008, 92:210-218.

26. Elsik CG, Tellam RL, Worley KC, Gibbs RA, Muzny DM, Weinstock GM, Adelson DL, Eichler EE, Elnitski L, Guigó R, Hamernik DL, Kappes SM, Lewin HA, Lynn DJ, Nicholas FW, Reymond A, Rijnkels M, Skow LC, Zdobnov EM, Schook L, Womack J, Alioto T, Antonarakis SE, Astashyn A, Chapple CE, Chen HC, Chrast J, Câmara F, Ermolaeva O, et al: The genome sequence of taurine cattle: a window to ruminant biology and evolution. Science 2009, 324:522-528.

27. Faraut $\mathrm{T}$ : Contribution of radiation hybrids to genome mapping in domestic animals. Cytogenet Genome Res 2009, 126:21-33.

28. Wade CM, Giulotto E, Sigurdsson S, Zoli M, Gnerre S, Imsland F, Lear TL, Adelson DL, Bailey E, Bellone RR, Blöcker H, Distl O, Edgar RC, Garber M, Leeb T, Mauceli E, MacLeod JN, Penedo MC, Raison JM, Sharpe T, Vogel J, Andersson L, Antczak DF, Biagi T, Binns MM, Chowdhary BP, Coleman SJ, Della Valle G, Fryc S, Guérin G, et al: Genome sequence, comparative analysis, and population genetics of the domestic horse. Science 2009, 326:865-867.

29. Lin A, Wang RT, Ahn S, Park CC, Smith DJ: A genome-wide map of human genetic interactions inferred from radiation hybrid genotypes. Genome Res 2010, 20:1122-1132.

30. Riera-Lizarazu O, Vales Ml, Ananiev EV, Rines HW, Phillips RL: Production and characterization of maize chromosome 9 radiation hybrids derived from an oat-maize addition line. Genetics 2000, 156:327-339.

31. Kynast RG, Okagaki RJ, Galatowitsch MW, Granath SR, Jacobs MS, Stec AO, Rines HW, Phillips RL: Dissecting the maize genome by using 
chromosome addition and radiation hybrid lines. Proc Natl Acad Sci USA 2004, 101:9921-9926.

32. Wardrop J, Snape J, Powell W, Machray GC: Construction of plant radiation hybrid panels. The Plant J 2002, 31:223-228.

33. Gao W, Chen ZJ, Yu JZ, Raska D, Kohel RJ, Womack JE, Stelly DM: Widecross whole-genome radiation hybrid mapping of cotton (Gossypium hirsutum L.). Genetics 2004, 167:1317-1329.

34. Hossain KG, Riera-Lizarazu O, Kalavacharla V, Vales MI, Maan SS, Kianian SF: Radiation hybrid mapping of the species cytoplasm-specific $\left(\mathrm{scs}^{\mathrm{ae}}\right)$ gene in wheat. Genetics 2004, 168:415-423.

35. Kalavacharla V, Hossain K, Gu Y, Riera-Lizarazu O, Vales MI, Bhamidimarri S, Gonzalez-Hernandez JL, Maan SS, Kianian SF: High-resolution radiation hybrid map of wheat chromosome 1D. Genetics 2006, 173:1089-1099.

36. Paux E, Sourdille P, Salse J, Saintenac C, Choulet F, Leroy P, Korol A, Michalak M, Kianian S, Spielmeyer W, Lagudah E, Somers D, Kilian A, Alaux M, Vautrin S, Bergès H, Eversole K, Appels R, Safar J, Simkova H, Dolezel J, Bernard M, Feuillet C: A physical map of the 1-gigabase bread wheat chromosome 3B. Science 2008, 322:101-104.

37. Michalak MK, Ghavami F, Gerard L, Yong G, Kianian SF: Evolutionary relationship of nuclear genes encoding mitochondrial proteins across four grass species andArabidopsis thaliana Maydica 2009, 54:471-483.

38. Sourdille P, Singh S, Cadalen T, Brown-Guedira GL, Gay G, Qi L, Gill BS, Dufour P, Murigneux A, Bernard M: Microsatellite-based deletion bin systems for the establishment of genetic-physical map relationships in wheat (Triticum aestivum L.). Funct Integr Genomics 2004, 4:12-25.

39. Francki MG, Walker E, Crawford AC, Broughton S, Ohm HW, Barclay I, Wilson RE, McLean R: Comparison of genetic and cytogenetic maps of hexaploid wheat (Triticum aestivum L.) using SSR and DArT markers. Mol Genet Genomics 2009, 281:181-191.

40. Givry S, Bouchez M, Chabrier P, Milan D, Schiex T: Carthagene: multi population integrated genetic and radiated hybrid mapping Bioinformatics 2005, 21:1703-1704.

41. Wenzl P, Suchánková P, Carling J, Simková H, Huttner E, Kubaláková M, Sourdille P, Paul E, Feuillet C, Kilian A, Dolezel J: Isolated chromosomes as a new and efficient source of DArT markers for the saturation of genetic maps. Theor Appl Genet 2010, 121:465-474.

42. Choulet F, Wicker T, Rustenholz C, Paux E, Salse J, Leroy P, Schlub S, Le Paslier MC, Magdelenat G, Gonthier C, Couloux A, Budak H, Breen J, Pumphrey M, Liu S, Kong X, Jia J, Gut M, Brunel D, Anderson JA, Gill BS, Appels R, Keller B, Feuillet C: Megabase level sequencing reveals contrasted organization and evolution patterns of the wheat gene and transposable element spaces. Plant Cell 2010, 22:1686-1701.

43. Kalavacharla V, Hossain KG, Riera-Lizarazu O, Gu Y, Maan SS, Kianian SF: Radiation hybrid mapping in crop plants. Adv Agron 2009, 102:199-219.

44. Endo TR, Gill BS: The deletion stocks of common wheat. J Hered 1996, 87:295-307.

45. Michalak M, Kumar A, Riera-Lizarazu O, Gu Y, Paux E, Choulet F, Feuillet C, Kumar S, Goyal A, Tiwari V, Dogramaci M, Hegstad J, Peckrul A, Kalavacharla V, Hossain K, Balyan HS, Dhaliwal HS, Gupta PK, Randhawa GS, Maan SS, Kianian SF: High-resolution radiation hybrid mapping in wheat: an essential tool for the construction of the wheat physical maps. In Proceedings of the 11th International Wheat Genetics Symposium proceedings. Edited by Apple R, Eastwood R, Lagudah E, Langridge P, Mackay M, McIntyre L, Sharp P. Sydney: Sydney University Press; 2008:64-67.

46. Neale MJ, Keeney S: Clarifying the mechanics of DNA strand exchange in meiotic recombination. Nature 2006, 442:153-158.

47. Borde V, Robine N, Lin W, Bonfils S, Géli V, Nicolas A: Histone H3 lysine 4 trimethylation marks meiotic recombination initiation sites. EMBO J 2009, 28:99-111.

48. Buard J, Barthès $P$, Grey $C$, de Massy B: Distinct histone modifications define initiation and repair of meiotic recombination in the mouse. EMBO J 2009, 28:2616-2624.

49. Zhang W, Wu Y, Schnable JC, Zeng Z, Freeling M, Crawford GE, Jiang J: High-resolution mapping of open chromatin in rice genome. Genome Res 2012, 22:151-162.

50. Perrella G, Consiglio MF, Aiese-Cigliano R, Cremona G, Sanchez- Moran E, Barra L, Errico A, Bressan RA, Franklin FC, Conicella C: Histone hyperacetylation affects meiotic recombination and chromosome segregation in Arabidopsis. Plant J 2010, 62:796-806.

51. Liu S, Yeh C-T, Ji T, Ying K, Wu H, Tang HM, Fu Y, Nettleton D, Schnable PS: Mutransposon insertion sites and meiotic recombination events co- localize with epigenetic marks for open chromatin across the maize genome. PLoS Genet 2009, 5:e1000733.

52. Rustenholz C, Choulet F, Laugier C, Safár J, Simková H, Dolezel J, Magni F, Scalabrin S, Cattonaro F, Vautrin S, Bellec A, Bergès H, Feuillet C, Paux E: A 3000-loci transcription map of chromosome $3 B$ unravels the structural and functional features of gene islands in hexaploid wheat. Plant Physiol 2011, 157:1596-1608.

53. Linger J, Tyler JK: The yeast histone chaperone chromatin assembly factor 1 protects against double-strand DNA-damaging agents. Genetics 2005, 171:1513-1522.

54. Goodarzi AA, Jeggo P, Lobrich M: The influence of heterochromatin on DNA double strand break repair: getting the strong, silent type to relax. DNA Repair 2010, 9:1273-1282.

55. Goodarzi AA, Noon AT, Deckbar D, Ziv Y, Shiloh Y, Löbrich M, Jeggo PA: ATM signaling facilitates repair of DNA double-strand breaks associated with heterochromatin. Molecular Cell 2008, 31:167-177.

56. Paux E, Roger D, Badaeva E, Gay G, Bernard M, Sourdille P, Feuillet $C$ Characterizing the composition and evolution of homoeologous genomes in hexaploid wheat through BAC-end sequencing on chromosome 3B. Plant J 2006, 48:463-474.

57. Paux E, Faure $S$, Choulet F, Roger D, Gauthier V, Martinant JP, Sourdille P, Balfourier F, Le Paslier MC, Chauveau A, Cakir M, Gandon B, Feuillet C: Insertion site-based polymorphism markers open new prespectives for genome saturation and marker-assisted selection in wheat. Plant Biotech J 2010, 8:196-210

58. Rodgers JL, Nicewander WA: Thirteen ways to look at the correlation coefficient. Am Stat 1988, 42:59-66.

59. Derrien T, Andre C, Galibert F, Hitte C: AutoGRAPH: an interactive web server for automating and visualizing comparative genome maps. Bioinformatics 2007, 23:498-499.

doi:10.1186/1471-2164-13-339

Cite this article as: Kumar et al:: DNA repair and crossing over favor similar chromosome regions as discovered in radiation hybrid of Triticum. BMC Genomics 2012 13:339.

\section{Submit your next manuscript to BioMed Central and take full advantage of:}

- Convenient online submission

- Thorough peer review

- No space constraints or color figure charges

- Immediate publication on acceptance

- Inclusion in PubMed, CAS, Scopus and Google Scholar

- Research which is freely available for redistribution 